\title{
La jerarquización del potencial turístico de la provincia de Huambo, República de Angola
}

The hierarchization of the tourism potential of the province of Huambo, Republic of Angola

\author{
"Elias Chilembo"" *
}

"Tania Caridad Carrazana Amador"2

\section{Resumen}

En este mundo fuertemente marcado por la creciente valorización de las especialidades locales y regionales, las comunidades deben asumir el potencial turístico que representa el patrimonio natural, cultural y ambiental, transformándolo en un producto turístico diferenciado y rentable. Huambo es una provincia de muchos encantos en el ámbito natural y cultural, por lo que el turismo puede ser un incentivo para el desarrollo de muchas de sus zonas rurales. Este trabajo de investigación analiza la valorización del potencial turístico de la provincia de Huambo y el uso eficaz y eficiente de los recursos turísticos para su desarrollo ambiental, social y económico, tomando en cuenta los niveles jerárquicos propuestos por Tabares en su metodología. El objetivo de este trabajo fue aplicar esta herramienta para analizar los atractivos turísticos naturales y culturales de la provincia de Huambo. Para ello, los procedimientos metodológicos se basaron en investigaciones bibliográficas y de campo con observación sistemática in situ y sin participación. Los datos recopilados se tabularon y analizaron de acuerdo con la metodología adaptada de la Organización Mundial del Turismo. Se han adoptado procedimientos de investigación aplicados, con el objetivo de un enfoque descriptivo, cualitativo y bibliográfico e investigación de campo, buscando recolectar información y analizar escenarios para describirlos e interpretarlos de acuerdo con las realidades de la provincia. En conclusión, es necesario tomar medidas para mejorar la infraestructura básica y turística de esta provincia para atraer flujos turísticos.

\begin{abstract}
In this world strongly marked by the growing appreciation of local and regional specialties, communities must assume the tourism potential represented by the natural, cultural and environmental heritage, transforming it into a differentiated and profitable tourism product. Huambo is a province of many natural and cultural charms, so tourism can be an incentive for the development of many of its rural areas. This research work analyzes the appreciation of the tourist potential of the Huambo province and the effective and efficient use of tourist resources for its environmental, social and economic development, taking into account the hierarchical levels proposed by Tabares in its methodology. The objective of this work was to apply this tool to analyze the natural and cultural tourist attractions of the Huambo province. For this, the methodological procedures were based on bibliographic and field investigations with systematic observation in situ and without participation. The collected data was tabulated and analyzed according to the methodology adapted from the World Tourism Organization. Applied research procedures have been adopted, with the objective of a descriptive, qualitative and bibliographic approach and field research, seeking to collect information and analyze scenarios to describe and interpret them according to the realities of the province. In conclusion, it is necessary to take measures to improve the basic and tourist infrastructure of this province to attract tutistic flows.
\end{abstract}

\section{Palabras clave/Keywords}

Turismo; jerarquía; desarrollo regional/Tourism, hierarchy, regional development

*Dirección para correspondencia: eliaschilembo@gmail.com

Artículo recibido el $15-08$ - 2020 Artículo aceptado el $07-12$ - 2020 Artículo publicado el 30 - 12 - 2020

Conflicto de intereses no declarado.

Fundada 2016 Unidad de Cooperación Universitaria de la Universidad Técnica de Manabí, Ecuador.

\footnotetext{
${ }^{1}$ Facultad de Economía, Profesor Auxiliar, Departamento de economía, Huambo, Angola, eliaschilembo@ @mail.com, +244 927669987, https://orcid.org/0000-0001-7098-1156

${ }^{2}$ Centro de Estudios de Técnicas de Dirección, CETED, Profesora Titular, Departamento de economía, La Habana, Cuba, tania@ceted.uh.cu, +53 56381025, https://orcid.org/0000-0001-9676-4379
} 


\section{Introducción}

El potencial turístico que tiene Angola para su desarrollo es relevante por las riquezas naturales y culturales que tiene el país, destacándose particularmente la provincia de Huambo, objeto de estudio del presente trabajo, dado por el hecho que sus riquezas pueden ponerse a disposición del desarrollo turístico, constituyendo así una fuente de ingresos más para el país y para sus habitantes. Su diversidad natural y cultural puede ser un destino turístico predilecto para nacionales y extranjeros, y convertirse en un sector estratégico para el desarrollo de la provincia.

De acuerdo con Ramírez (2015), el potencial turístico de una región depende de la evaluación que se realiza sobre los recursos, así como del nivel de estructuración de sus atractivos en productos.

De acuerdo con Ramírez (2015) citado por el Servicio Nacional de Turismo SERNTUR (2000), el potencial turístico lo determina la forma en que la oferta de productos y servicios turísticos de una localidad se adapta para satisfacer las necesidades actuales de esparcimiento y recreación de los turistas nacionales e internacionales; para identificar el potencial turístico de un territorio, es necesario realizar un inventario de los recursos con los que cuenta una zona determinada, a fin de conocer sus características. Por tanto, se puede afirmar que, la evaluación de las potencialidades debe estar en función de la satisfacción de los clientes, de acuerdo con los recursos con que se cuenta.

Según Almeida (2009) la evaluación del potencial turístico considera aspectos importantes para la oferta turística que se pueden dividir en factores naturales, socioeconómicos y culturales, tales como:

Factores naturales: situación geográfica, tamaño del territorio, condiciones climáticas, situación hidráulica, paisajes, fauna y flora.

Factores socioeconómicos: estructura económica, estructura sociodemográfica (distribución de edad, emigración, distribución socioprofesional, etc.) y estructura político-administrativa.

Factores culturales: historia, costumbres/productos artesanales locales, configuración de los lugares, monumentos y curiosidades, lugares para visitar, visitas guiadas, atracciones y manifestaciones culturales.

En la evaluación se debe tener en cuenta además la infraestructura, los servicios y las ofertas diversas, tales como:

Infraestructuras y servicios disponibles: equipamientos (agua, gas, electricidad, tratamiento de residuos, etc.), transporte (red de carreteras, red ferroviaria, transporte público, etc.), servicios de comercio y de salud.

Oferta de alojamiento: capacidad total, distribución de la oferta de alojamiento de camas y tipos de alojamiento, calidad y precios, etc.

Oferta de restauración: capacidad total, distribución local de los restaurantes, calidad y precios.

No obstante, cuando se realiza un inventario del potencial turístico de una localidad o territorio, es necesario, no solo enfocarse en las tendencias que esperan los turistas, sino también establecer un contacto más cercano con las tradiciones, con las personas y con la cultura de una zona determinada. Como, por ejemplo, las fiestas típicas de la región, las de fin de año (Navidad y Año Nuevo), los visitantes internacionales, sobre todo, aprecian mucho observar de cerca la vida campesina en la propia localidad, estar en contacto con las poblaciones rurales, consumir frutos frescos directamente de los árboles, con el disfrute del ambiente natural.

Como tal, Ramírez (2015), afirma que toda la zona que considere desarrollar o ampliar el turismo, debe evaluar cuidadosamente sus recursos turísticos. Entre estos figuran todos los tipos de atracciones y actividades actuales o posibles relacionados con el medio ambiente natural, el patrimonio cultural y los rasgos específicos de una zona, como actividades económicas, sitios urbanos, entornos rurales, servicios de salud, lugares religiosos, instalaciones y lugares turísticos ya en funcionamiento, infraestructuras de transporte y disponibilidad de mano de obra calificada.

Según Dely (2015), los espacios rurales, donde se albergan valores etnológicos con patrimonio cultural, deben considerarse como un valor añadido, ya que satisfacen en la misma medida las expectativas de los visitantes.

Cruz (2010) afirma que la atracción turística está compuesta por toda experiencia vivida durante la estadía, las actividades que buscan mejorar o incrementar las actuaciones de un destino/local para ocupar los tiempos libres de los visitantes o satisfacer sus necesidades.

Para Castillo (2012), recurso turístico, por lo tanto, es todo elemento natural, toda actividad humana o todo producto antropológico que pueda motivar un desplazamiento turístico, cuyo móvil básico es la curiosidad o posibilidad de realizar una actividad física o intelectual. En otras palabras, recurso turístico es aquel elemento con potencial turístico que se presenta como un atractivo turístico para atender a los turistas.

De acuerdo con Almeida \& Araújo (2017), un elemento natural no es un recurso. Es necesario una intervención del hombre cualquiera que sea su naturaleza y dimensión que le atribuya la capacidad de satisfacer necesidades. Un mar, un paisaje, una playa, o clima, son fuentes de atracción y provocan el desplazamiento de personas, y responden a necesidades humanas, pero esta necesidad sólo es satisfecha mediante una intervención humana que convierta estos recursos en atractivos turísticos.

Según Cárdenas (2006), la jerarquización determina la calidad del atractivo turístico y el tipo de mercado que puede atraer. El autor continúa y afirma que, en lo concerniente al entorno físico, es de suma importancia el estudio del clima, incluso indica cómo puede ser el diseño del proyecto de inversión.

Para Rodríguez (s/f), la jerarquización de potencialidad surge para implementar la evaluación de potencialidad turística de los recursos. Su relevancia radica en que los recursos no necesariamente deben contar con equipamiento e infraestructuras propias, sino qué centros de poblaciones pueden cumplir la función de soporte del recurso y de la actividad turística.

Por tanto, la jerarquización puede ser definida como la estructura que se establece en orden a su criterio de subordinación entre personas, animales, naturaleza, infraestructura, y que se deben establecer acciones que permitan presentar sus potencialidades, así como sus diferentes niveles, para el desarrollo del turismo de naturaleza y cultural.

La política de desarrollo y fomento del turismo en la provincia de Huambo es resultado de una investigación donde se determinó la estructura de los criterios basada en la jerarquización según Cárdenas (2006). La presente investigación tuvo como objetivo utilizar la metodología de este autor, como herramienta para analizar los atractivos turísticos de la provincia de Huambo y establecer las potencialidades a desarrollar.

\section{Materiales y Métodos}

Los factores que determinaron el análisis del potencial turístico de la provincia de Huambo son: el valor de los atractivos, su calidad, 
accesibilidad y equipamiento según Ribeiro \& Vareiro (2006) citando a Cerro (1992-1993)

Los datos recogidos fueron tabulados y analizados según la metodología adaptada de la Organización Mundial del Turismo - OMT. Se han adoptado procedimientos de investigación de carácter aplicado, con enfoque descriptivo, cualitativo y bibliográfico e investigación de campo buscando recoger información y analizar escenarios para describirlos e interpretarlos de acuerdo con las realidades de la provincia de Huambo.

Cerro (1993) también comenta las posibilidades de aplicación del inventario turístico y el análisis del paisaje, sin embargo, el autor da gran importancia en gran parte de su trabajo a técnicas de evaluación de los recursos turísticos, que se subdividen en:

- Evaluación analítica del potencial turístico.

- Evaluación económica de los recursos.

- Preferencias de los usuarios como medida de evaluación del turismo.

Además de Cerro (1993), quien dedicó un trabajo completo al tema y es el único identificado en la literatura internacional con tal característica, en la tabla 1 se presentan algunas referencias teórico metodológico que abordan explícitamente el tema aquí estudiado, y que han subvencionado el enriquecimiento de la discusión y la propuesta metodológica (objeto) de este trabajo de investigación.

Tabla 1.

Principales características de las referencias teórico-metodológicas identificadas

Referencial

Teórico-Metodológico Características principales

Gearing, Swart y Var o - Método indirecto de preferencia

Índice de Atracción de usuarios (de la búsqueda con

Turística (TAI)

(Fagllari \& Almeida, 2004) expertos, que deben ser elegidos cuidadosamente).

- Enfoque en los atractivos turísticos.

- Uso de pesos y escalas numéricas para las evaluaciones.

- Aparente simplicidad y flexibilidad con respecto al uso.

Análisis de los factores de - Centrarse en la investigación de productividad de la mercado y ubicación del proyecto Ubicación de los proyectos turístico.

turísticos en Cárdenas - Análisis de los factores decisivos, (1994)

importantes y deseables.

- El uso de pesos para cada conjunto de factores y la asignación de puntuaciones para la evaluación.

- Se basa en la teoría del espacio turístico de Boullón y en la evaluación y jerarquización de las atracciones turísticas del Centro.

Entrenamiento Turístico Interamericano (CICATUR) de la Organización de los Estados Americanos (OEA)

Índice del potencial - Campo de estudio: Sudáfrica, turístico de Ferrario (1979, Lesoto y Suazilandia.

apud Pearce, 1991) - Combinación de varias metodologías.

Amplio inventario de la oferta turística para los guías turísticos,

\begin{tabular}{|c|c|}
\hline & $\begin{array}{l}\text { basado en dos criterios: atractivo } \\
\text { y disponibilidad. } \\
\text { - Uso de fórmulas matemáticas. } \\
\text { Incluye la investigación de la } \\
\text { demanda turística. }\end{array}$ \\
\hline $\begin{array}{l}\text { Medida de atracción } \\
\text { turística de Var, Beck y } \\
\text { Loftus (Cerro, 1993) }\end{array}$ & $\begin{array}{l}\text { - Campo de estudio: Columbia } \\
\text { Británica (Canadá) } \\
\text { - } \quad \text { Uso de fórmulas matemáticas. } \\
\text { - } \quad \text { Selección de criterios para la } \\
\text { valoración de los atractivos } \\
\text { turísticos de la zona a evaluar. } \\
\text { - } \\
\text { Asignación de pesos específicos } \\
\text { para cada uno de los criterios de } \\
\text { acuerdo con su propio atractivo } \\
\text { turístico. }\end{array}$ \\
\hline $\begin{array}{l}\text { Evaluación de los recursos } \\
\text { turísticos de la OMT } \\
\text { (Cerro, 1993) }\end{array}$ & 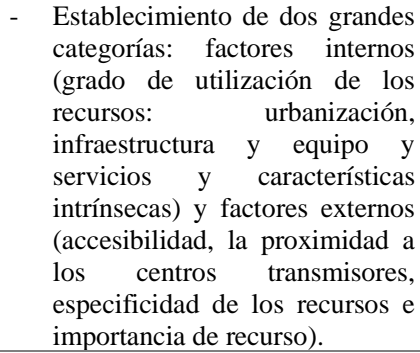 \\
\hline $\begin{array}{l}\text { Adaptación de la } \\
\text { metodología de la jerarquía } \\
\text { de recursos turísticos de la } \\
\text { OEA para su aplicación en } \\
\text { la Comunidad Autónoma de } \\
\text { La Rioja por Álvarez y } \\
\text { Cerro (Cerro, 1993) }\end{array}$ & $\begin{array}{l}\text { - Campo de estudio: Comunidad } \\
\text { Autónoma de La Rioja/España. } \\
\text { - Uso de fórmulas matemáticas. } \\
\text { - Introducción de un factor de } \\
\text { ponderación en relación con la } \\
\text { zona en la que se encuentra el } \\
\text { recurso (que corrige la jerarquía } \\
\text { inicial concedida el llamamiento) } \\
\text { y tres elementos. }\end{array}$ \\
\hline
\end{tabular}

Fuente: Elaboración propia.

El estudio se realizó en la provincia de Huambo, y tuvo una duración de seis meses, se revisó la documentación para la búsqueda y análisis de la información, partiendo de la investigación y pesquisa de fuentes bibliográficas.

Las analogías históricas, a partir de las cuales se analiza la evolución de las actividades relacionadas con la calidad, desde las más elementales hasta las más complejas, en permanente cambio, dado el carácter eminentemente económico de la calidad, así como el proceso evolutivo de los costos de la calidad y de la contabilidad de gestión.

- Análisis y síntesis; el objeto tiene múltiples elementos que es necesario precisar (separar) y, además, integrar.

- Entrevistas, la dinámica de grupos, y las consultas a expertos, así como los métodos estadísticos para el procesamiento de la información disponible.

Aunque varios autores confirman la necesidad de realizar estudios sobre las potencialidades del turismo pocos han avanzado hacia la elaboración de puntos de referencia para tal análisis, especialmente para Angola, observando una casi total inexistencia de investigaciones sobre el tema aquí estudiado.

\section{Resultados}

\subsection{Potencialidades Turísticas}

La provincia de Huambo tiene un conjunto de potencialidades que le permite desarrollar un turismo de naturaleza, a través de la gestión

La jerarquización del potencial turístico de la provincia de Huambo, República de Angola

Chilembo, Carrazana Amador 
integrada, que facilita la vinculación con el turismo cultural, por sus fuentes y riquezas naturales y su cultura popular. El Departamento de Turismo, Hotelería y Deportes de Huambo, destaca 116 puntos de interés turístico de esta Provincia, de acuerdo con los datos de la Dirección Provincial de Comercio (Direç̧ão Provincial do Comercio, 2017).

Teniendo en cuenta las potencialidades turísticas existentes en esta provincia, sería muy importante desarrollar un plan de jerarquización, para realizar una explotación conforme a las potencialidades con que cuenta esta región de Angola para el turismo de naturaleza y cultural. Esta belleza natural y cultural que la región posee es parte de los innumerables recursos turísticos.

\subsection{Atractivos turísticos de la provincia de Huambo}

La región de Huambo está compuesta por un conjunto de encantos naturales que ofrecen una diversidad de atractivos naturales y culturales, que permiten descubrir y vivir experiencias con el medio ambiente y convivir con las personas locales.

Huambo ofrece espacios geográficos que invitan a los turistas a practicar la aventura, tal como subir las montañas, así como el disfrute de las comidas locales, danzas y música tradicional de la región.

Sobre los encantos de la provincia de Huambo y en particular los encantos de la ciudad de Huambo, se puede destacar el parque de la cultura con las estatuas de Norton de Matos (fundador de la ciudad durante el período colonial) y sus cinco esposas que eran las cinco virtudes de ese estadista portugués. El parque de la cultura es sin duda una postal de la ciudad capital de esa provincia. Además, se puede destacar el parque Agostinho Neto (monumento del primer presidente de Angola y fundador de la nación Angolana). Las iglesias de Nuestra Señora de Fátima, la Sé Catedral, la iglesia de la Peregrinación de Cristianos Católicos en Caala, el hermoso edificio de la Iglesia Adventista del Séptimo día de Huambo, los museos y bibliotecas provinciales, así como las mediatecas, el hermoso lugar del Granja Por de Sol, el Cantiño de la Paz, la Represa de Cuando, el Moro de Moco (el punto más alto del país), entre otros, son los encantos que hacen a la provincia muy competitiva y con muchas ventajas, en relación a las demás provincias del país.

Es importante señalar que estos recursos turísticos, por sí solos, no cuentan con instalaciones necesarias para atraer a los visitantes, pero sólo cuando se desarrollan con equipamientos y servicios turísticos (como hoteles, restaurantes, y vías de comunicación) se convierten en atractivos turísticos en plenitud.

\subsection{Potencialidades turísticas de la provincia}

Según Fernando (2015), en el documento intitulado HuamboWelcome to Angola (2017), Huambo tiene un área total de $35,270 \mathrm{~km}^{2}$, con una población de $1,896,147$, de clima tropical, de la altitud, y temperatura de $19^{\circ} \mathrm{C}$. La provincia se encuentra a los 1,700 metros por encima del nivel del mar y en invierno (desde mayo hasta agosto), hace mucho frio, principalmente en la noche, cuando la temperatura llega hasta $4^{\circ} \mathrm{C}$.

Antes de la guerra, Huambo era considerado el segundo mayor parque industrial y comercial de Angola y actualmente, a pesar de la situación de crisis económica, se aprecia que el gobierno de la provincia busca la revitalización del turismo, aunque registra un crecimiento moderado que le permite recuperarse de los efectos de la mencionada etapa y de la actual crisis que atraviesa el país.

La provincia de Huambo es atractiva a los turistas por su rica gastronomía, cultura, clima agradable y cuenta con dos estaciones al año, estación seca y estación lluviosa. La depresión es intermedia y cuenta con recursos hídricos, lo que permite la actividad agrícola y forestal, disponiéndose de millares de hectáreas plantadas de eucalipto y cedros, lo que en el pasado no muy distante sustentaba la fábrica de papel, la llamada "fábrica de Celulosa" en Alto Katumbela.

Los lugares turísticos más visitados en la provincia de Huambo son, por supuesto, los diversos sitios patrimoniales y, los acervos culturales de la provincia, así como los encantos maravillosos de la Comuna de Alto Hama. Esta Comuna cuenta con las aguas frías y calientes, recomendadas para sanar determinadas enfermedades. Otro encanto en la provincia de Huambo en términos de acervo cultural y riqueza tradicional es el reino tradicional de Bailundo, donde se salvaguarda una tradición y cultura impar en el mundo (la práctica de ceremonias de akokotos, donde preserva los cuerpos de distintas dinastías) y se encuentra el rey. La provincia cuenta con un número reducido de hoteles y servicios de restaurantes, y los servicios disponibles en la región son muy costosos, lo que desmotiva a los turistas y al desarrollo del turismo en general.

La localización geográfica de esta provincia es muy importante, con las vías de comunicación que atraviesan la ciudad capital para otras provincias del país, y conectando con otros países como Namibia, Zambia y la República Democrática de Congo, a través del tren.

Huambo tiene 11 municipios, los cuales son: Huambo, Bailundo, Mungo, Tchinjenje, Ekunha, Tchicala-Tcholoanga, Ucuma, Cachiungo, Longonjo, Lombuimbale y Caála.

En este artículo se propone una clasificación jerárquica teniendo en cuenta las potencialidades turísticas que ofrece la provincia de Huambo y obedeciendo la jerarquización propuesta por Cárdenas (2006).

\subsection{Niveles de jerarquización de las potencialidades de la provincia de Huambo}

Los niveles de jerarquización planteados por Organización Mundial del Turismo (OMT) para determinar los recursos turísticos no sólo clasifican como atractivos, sino que valoran sus cualidades, rasgos y/o componentes y asignándoles jerarquías, tal como lo expone Cárdenas (2006), establecidas por orden descendiente. Así en la provincia de Huambo la jerarquización puede clasificarse como:

\section{Jerarquía 5}

Se refiere a un atractivo excepcional y de gran significación para el mercado turístico internacional, capaz por sí solo de motivar una importante corriente de visitantes (actual o potencial), cuantificada como un porcentaje del total de la demanda del país, o de algún mercado específico. Equivalente a recurso único en el mundo.

En el caso de Huambo, este tipo de jerarquía se encuadra con la cultura que se practica en reino de Bailundo, donde los reinos y dinastías tradicionales obedecen a la práctica tradicional de los Vakokotos, la cual es una práctica única a nivel mundial, conjugada con la belleza natural de una montaña Bailundo, lugar donde los reyes de esta dinastía fueron enterrados, después que les cortaran sus cabezas y las guardaran en un lugar secreto y específico del palacio tradicional, llamado Ombala. Visitantes de todo el país, así como de otras partes del mundo tienen el privilegio de visitar el reino y los Vakokotos después de pagar una tasa simbólica en moneda nacional de Angola. 


\section{Jerarquía 4}

Atractivo con rasgos excepcionales en un país, capaz de motivar una corriente (actual o potencial) de visitantes del mercado interno o externo, pero en menor porcentaje que los de jerarquía 5 , ya sea por sí solo o en conjunto con otros atractivos contiguos. Equivalente a recurso único en el país y en el caso de la provincia de Huambo, se identifica con el moro de Moko (montaña de Moko), que es el punto más alto de Angola, donde visitantes o excursionistas escalan semanalmente, para disfrutar de sus encantos.

\section{Jerarquía 3}

Atractivo con algún rasgo llamativo, capaz de interesar a visitantes de larga estancia, ya sea del mercado interno o externo, que hubiesen llegado a su zona por otras motivaciones turísticas; o de motivar corrientes turísticas locales (actuales y potenciales). Equivalente a recurso único en una jurisdicción a nivel subnacional.

En el centro de la ciudad de Huambo y específicamente en el jardín de la Cultura se encuentran las estatuas del Norton de Matos (el fundador de la ciudad de Huambo), así como las estatuas de sus cinco esposas y que por su características atractivas y peculiares mueve visitantes que vienen a la provincia por otros motivos, tales como negocios, peregrinaciones religiosas, búsqueda de salud u otros motivos y se motivan para admirar estas figuras de gran importancia, donde se asienta esta bella ciudad.

\section{Jerarquía 2}

Atractivos con méritos suficientes para ser considerados importantes para el mercado interno, pero sin condiciones para el turismo y que forman parte del patrimonio turístico. Equivalente a recurso único en una localidad. Análogamente en Huambo, se encuentra la plaza Agostinho Neto, donde se encuentra la estatua del fundador de la República de Angola y primer presidente del país, el Dr. Antonio Agostinho Neto. Excursionistas y profesores de las escuelas primarias visitan constantemente este lugar para explicar a sus alumnos de niveles primarios la historia de Angola, la lucha armada por la independencia y la dedicación y empeño que Agostinho Neto tuvo para libertar su pueblo de la opresión portuguesa, que deseaba el control del territorio angolano, reduciéndole a una provincia de Portugal.

\section{Jerarquía 1}

Atractivos sin méritos suficientes para considerarlos en las jerarquías anteriores, pero que igualmente forman parte del patrimonio turístico como elementos que pueden completar a otros de mayor jerarquía en el desarrollo y funcionamiento de cualquiera de las unidades que integran el espacio turístico. Equivale a recursos complementarios. En la provincia de Huambo se tiene como ejemplo las piedras de Ndala Candumbo, donde se encuentra la tumba de Huambo Kalunga, que fue un rey tradicional, que le da su nombre a esta provincia. Historiadores y antropólogos visitan la tumba de Huambo Kalunga regularmente para consolidar sus conocimientos.

\section{Jerarquía 0}

Atractivos cuyas cualidades no permiten incorporarlos a la jerarquía 1, que es el umbral mínimo de jerarquización. Equivalente a recurso sin características relevantes (no es un recurso turístico). Como ejemplo de este grado de jerarquía, se destaca el buen clima de la provincia. (que es normalmente de 16 a $22^{\circ} \mathrm{C}$ casi todo el tiempo), acompañada de su belleza natural, llena de encantos admirables, así como el pueblo pacífico y alegre característico de la provincia. Igualmente, en la provincia de Huambo se encuentra el Santuario de Nuestra Señora del Monte da Caála, situado en el Monte Mbandjela. Construido en 1927 por el Padre Católico Domingos Vieira Baião, misionero de la Congregación de los Padres del Espíritu
Santo, este lugar es utilizado para realizar peregrinaciones religiosas en búsqueda de salud.

Existen muchos recursos naturales, pero que deberían desarrollarse y otorgarles valor o atractivo turístico. Se verifica que existe muy poca actividad recreativa, especialmente las danzas tradicionales, cines, teatro y otras actividades de animación en Huambo que, siendo además una ciudad universitaria, no responde aun a las necesidades de los jóvenes estudiantes. Se observa en la provincia una inadecuada infraestructura para cumplir las exigencias del turismo receptivo.

A continuación, se ilustra el resumen de los niveles de jerarquización en la provincia de Huambo:

Tabla 2.

Niveles de jerarquización en Huambo

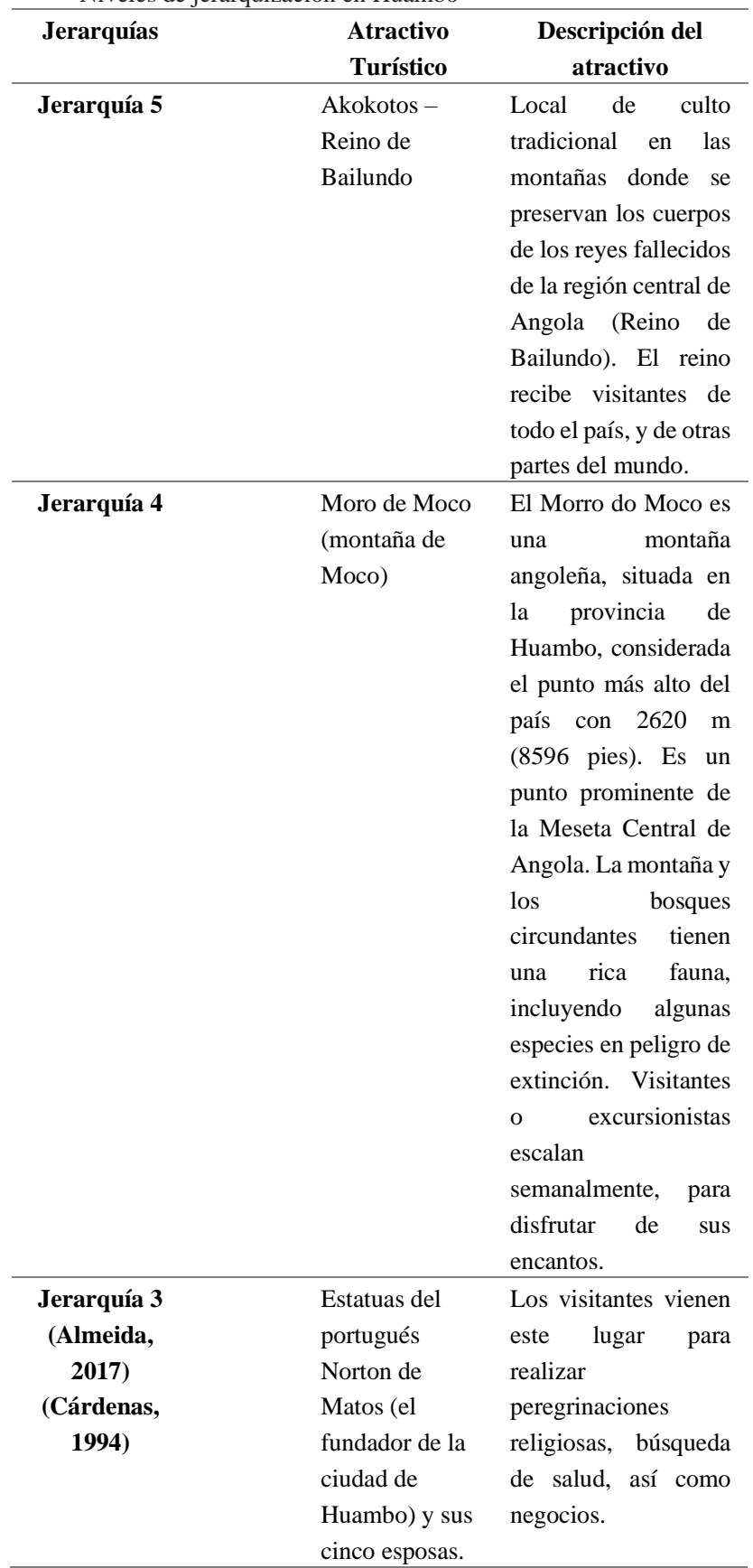




\begin{tabular}{|c|c|c|}
\hline Jerarquía 2 & $\begin{array}{l}\text { Plaza } \\
\text { Agostinho } \\
\text { Neto }\end{array}$ & $\begin{array}{l}\text { Lugar donde se } \\
\text { encuentra la estatua } \\
\text { del fundador de la } \\
\text { República de Angola } \\
\text { y primer presidente } \\
\text { del país, el Dr. } \\
\text { Antonio Agostinho } \\
\text { Neto. }\end{array}$ \\
\hline Jerarquía 1 & $\begin{array}{l}\text { Piedras de } \\
\text { Ndala } \\
\text { Candumbo }\end{array}$ & $\begin{array}{l}\text { Lugar donde se } \\
\text { encuentra la tumba de } \\
\text { Huambo Kalunga, } \\
\text { que fue un rey } \\
\text { tradicional, que le da } \\
\text { su nombre a esta } \\
\text { provincia de Huambo. } \\
\text { Forma parte del } \\
\text { patrimonio turístico } \\
\text { nacional. }\end{array}$ \\
\hline Jerarquía 0 & $\begin{array}{l}\text { El Santuario de } \\
\text { Nuestra Señora } \\
\text { del Monte da } \\
\text { Caála, situado } \\
\text { en el Monte } \\
\text { Mbandjela. }\end{array}$ & $\begin{array}{l}\text { Construido en } 1927 \\
\text { por el Padre Católico } \\
\text { Domingos Vieira } \\
\text { Baião, misionero de } \\
\text { la Congregación de } \\
\text { los Padres del Espíritu } \\
\text { Santo, este lugar para } \\
\text { realizar } \\
\text { peregrinaciones } \\
\text { religiosas, búsqueda } \\
\text { de salud. }\end{array}$ \\
\hline
\end{tabular}

Fuente: Elaboración propia.

\section{Discusión}

El potencial turístico que tiene Angola para su desarrollo es relevante por las riquezas naturales y culturales que tiene el país, destacándose particularmente la provincia de Huambo, objeto de estudio del presente trabajo, dado por el hecho que sus riquezas, tanto naturales, como culturales pueden ponerse a disposición del desarrollo turístico, constituyendo así una fuente de ingresos más para el país y para sus habitantes.

La provincia de Huambo presenta grandes potencialidades turísticas, por sus paisajes y naturaleza, pero hay necesidades y urgencia de fomentar estas potencialidades y mejorar la calidad de los servicios y accesos, para que la provincia pueda realmente lograr ser un destino turístico.

Esta provincia cuenta también con atractivos diversos para la realización de deportes y recreaciones al aire libre, lo cual es necesario explotar. Las autoridades gubernamentales de la provincia, así como los empresarios se han dado cuenta de este potencial turístico y ya hay programas de desarrollo en esta rama de la industria turística, pero existe gran necesidad de dinamizar el sector responsable y convertir los proyectos en realidad.

La provincia de Huambo es una región con alta biodiversidad natural y cultural que incentiva el desarrollo de la actividad turística, que puede llegar a constituir un destino turístico preferido por visitantes nacionales y extranjeros, y convertirse en un sector estratégico para el desarrollo de la provincia.

En ese artículo se determinan las potencialidades y jerarquías para el desarrollo de las actividades turísticas en la provincia de Huambo. Para un turismo de naturaleza y cultural capaz de atraer turistas nacionales y extranjeros se hace necesario fundamentar los criterios básicos para el desarrollo sostenible del turismo. Para ello, se propone:

- Es prioritario mejorar la infraestructura básica y turística, tanto vial como de equipamiento si se pretende atraer importantes flujos de turistas.

- Es necesario crear condiciones higiénicas, señalética, y la actitud de los lugareños hacia los turistas es grandemente relevante para el desarrollo turístico de la provincia.

- Se sugiere la creación de rutas y circuitos turísticos atractivos para la tercera edad.

\section{Referencias bibliográficas}

Almeida, M. (2009). Matriz de Avaliação do Potencial Turistico de Localidades Receptoras. Turismo em Análise.

Almeida, P., \& Araújo, S. (2017). Introdução a Gestão de Animação Turistica. Lisboa: LIDEL.

Cárdenas, T. F. (1994). Proyectos turísticos, localización e inversión. 1a ed. Mexico: Trillas.

Cárdenas, T. F. (2006). Proyectos turísticos. Localización e inversión. 2a ed. México: Trillas.

Castillo, H. M. (2012). Recursos Turísticos. Introducion a los recursos Turisticos. México: Cas12.

Cerro, F. L. (1993). Técnicas de evaluación del potencial turístico. Madrid: Madrid; MICYT, Centro de Publicaciones, DL.

Cruz, R. (2010). Evaluación De Los Recursos Turisticos. Iquítos, Perú.: Instituto de Investigación de Amazonia Peruana.(IAP).

Dely, M. B. (2015). Propuesta de un Sistema de Gestión de Calidad en Departamento de Recursos Humanos de la empresa Binários SRL,(Tesis de Maestria en Gerencia de Recursos Humanos. República Domicana: Santo Domingo, DO - Universidad APEC.

Direcção Provincial do Comercio, H. e. (Janeiro 2017). Caracterização Geral da Província do Huambo. Huambo: Governo Provincial do Huambo.

Fagllari, G. S., \& Almeida. (2004). Análise de actkividade e hierarquisação de atractivos: sistematização de métodos e proposta para atractivos culturais. Faculdade Senac de Turismo e Hotelaria de São Paulo.

Fernando, M. (2015). O Turismo em Angola. Luanda: Soluções gráficas Lda.

Pearce, D. (1991). Desarrollo Turístico: su planificación y ubicación geográficas. México: Trillas.

Ramírez, R. C. (2015). Evaluación del Potencial en Municipios Turísticos a través de Metodologias Participativas. El caso de los municipios de la Zona Norte de Colima. México: Universidad de Colima.

Rodríguez, C. (s/f). La jeraquización De Los Recursos En Áreas Turisticas No tradicionales. Bahia Blanca: Departamento de Geografia y Turismo. Universidad Nacional de Sur.

SERNTUR. (2000). Turismo Cultural. Orientaciones para su desarrollo. Santiago: Publicaciones Gobierno de Chile. 


\section{Glosario}

OMT (Organización Mundial de Turismo)

SERTUR (Servicio Nacional de Turismo)

\section{Agradecimientos}

Agradezco a mi esposa Inocència Pedro matapalo Chilembo y al Dr. José Álves Casaco por el apoyo prestado en la revisión del idioma español, así como el apoyo moral. 